\title{
THE CASE FOR A RECIPROCAL HEALTH CARE AGREEMENT BETWEEN AUSTRALIA AND SOUTH KOREA
}

\author{
Stephanie Doris Short', Hyo-Young Lee², Mi-Joung Lee3, Eunok Park4, Farah Purwaningrum5 \\ 1. Faculty of Medicine and Health, the University of Sydney, Australia \\ 2. Dongseo University, South Korea \\ 3. Faculty of Medicine and Health, the University of Sydney, Australia \\ 4. College of Nursing, Jeju National University, South Korea \\ 5. Sydney Asia Pacific Migration Centre, the University of Sydney, Australia
}

Correspondence: stephanie.short@sydney.edu.au

\section{ABSTRACT}

\section{OBJECTIVES}

This study presents the case for a reciprocal health care agreement (RHCA) between Australia and South Korea.

\section{DESIGN AND SETTING}

The research utilised a qualitative social scientific methodology. Document analysis was conducted on government reports, official statistics and media articles in English and Korean.

\section{MAIN OUTCOMES}

In Australia, the Health Insurance Act 1973 enables health care agreements with 11 nations, however, Korea has no similar legislation in place. Therefore, Korea would need to build a broader consensus on the need for a RHCA in full, based on the precedent of Australia's agreements with other nations, as well as on the Korean Pension Act, which has enabled reciprocal (equal treatment among the countries) pension agreements with 28 nations through an exceptive clause.

\section{RESULTS}

The active government commitment and involvement of the Ministry of Health and the Department of Foreign Affairs and Trade in Australia, and of the Ministry of Health \& Welfare and Ministry of Foreign Affairs in South Korea, would be essential for a successful RHCA process to come to fruition.

\section{CONCLUSIONS}

While a potential health care agreement between Australia and Korea would constitute a significant step forward in strengthening people-to-people links between these two significant trading partners in the spirit of health diplomacy, the feasibility at the current time is very low indeed.

\section{KEYWORDS}

Reciprocal Health Care Agreements, Australia, Republic of Korea, Health policy analysis 
WHAT ARE RECIPROCAL HEALTH CARE AGREEMENTS?

This study was initiated by Koreans living temporarily in Australia who were aware of the Reciprocal Health Care Agreements between other countries and Australia. An international team of social science, health professional and health administration academics sought and attracted support for the conduct of this social scientific research study from the Australia-Korea Foundation through the Australian Department of Foreign Affairs and Trade in 2015. The study presents the case for a reciprocal health care agreement as a policy advocacy study; as such the aim is to create an opening for social change through greater public awareness and support for the issue.[1]

Reciprocal Health Care Agreements (RHCAs) enable the provision of medical treatment between countries when the people of these countries travel or visit their counterparts. The medical service is to be provided within the country without purchasing additional travel insurance or being resident in the country party to the agreement. If there is continuity in the agreement, the exchange between the two countries can be strongly maintained, and there would be the protection of the visitors as well as the protection of their health rights. South Korea has not yet signed a mutual health care agreement with any other country, Australia currently has mutual health care agreements with 11 countries: Belgium, Finland, Italy, Malta, the Netherlands, New Zealand, Norway, the Republic of Ireland, Slovenia, Sweden, and the United Kingdom. [2] To be eligible for reciprocal benefits a visitor has to be a resident of one of the above countries. Visitors from Italy or Malta must be residents and citizens of their home country. These visitors are only entitled to Medicare coverage for the first six months in Australia. Residents from other countries are entitled to benefits for the duration of their stay in Australia. [2]

\section{BACKGROUND TO THE STUDY: THE KOREA- AUSTRALIA FREE TRADE AGREEMENT (KAFTA)}

South Korea is a significant destination for Australia's national resource exports such as coal, iron ore, and copper, in addition to a range of agricultural goods. [3] These two Governments secured the Korea-Australia Free Trade Agreement (KAFTA) in 2014, [4] as a preferential trade agreement in an attempt to ensure that Australian and Korean exporters gained a competitive edge for their exports, with nearly all import taxes (tariffs) on goods and services eliminated over time. (4) Moreover, the number of Australians who are visiting South Korea, facilitated by way of KAFTA has increased rapidly. [5) Close to 230,000 Australians visited South Korea in 2019, of which the majority of visitors were aged less than 30 years. [6] This comprised 1.3 percent of Korea's 17.5 million inbound visitors in 2019, where China was the major source country of short-term visitors.

Recent decades have generally seen an ongoing increase of visitor arrivals to Australia. The most recently available statistics on travel movements of persons arriving in Australia for short term visits, that is less than 1 year, indicate the highest number of arrivals on record in 2018-19, when Australia welcomed 9.3 million short-term visitors to Australia from overseas. [7] In 2018-19, prior to the COVID-19 pandemic, China was the largest source country, with over 1.4 million visitors. Among the top ten source countries i.e., China, New Zealand, USA, UK, Japan, Singapore, Malaysia, India, Hong Kong, South Korea, there has been particularly strong growth from Asian countries, including South Korea, which saw a $42 \%$ increase in visitors in the last decade. [6]

In 2018-2019 the most frequently cited reason for South Korean visitors visiting Australia was holiday (47\%), visiting friends and relatives (30\%), business (7\%) and education (7\%), with women predominant in each category, except business. Those travelling for education and employment stayed the longest, with those travelling for business staying the shortest period. 'Warhol' (Working Holiday) is a system in which young people aged 18 to 30 gain experience with local culture and life through tourism, employment, and language training. Many Korean college students visit Australia as a "Warholer" or working holiday visa holders with about 18,000 Koreans staying in 2005 and nearly 40,000 in 2009. [8]

The largest number of "Warholers" in Australia are from South Korea. As of 2017, the number exceeded more than $50 \%$ of the total number of "Warholer". [8] Most working holiday visa holders work in jobs with some risk of injury, such as working in farmlands or meat processing factories in rural areas. [9] Furthermore, most of these people will return after 1-2 years to South Korea to participate in economic activities in South Korea. [5] Should their health rights not be adequately protected during their stay in Australia, they may have considerable medical needs to be addressed 
within the health insurance system in South Korea after returning home.

In sum, this a timely study, as comparable numbers of Koreans visit Australia compared with Australians who visit South Korea. Of particular significance for this study is the increase in the number of visitors between South Korea and Australia over the last decade. $[9,10]$ Thus, a possible reciprocal health care agreement (RHCA) would enhance the accessibility of medical services to visitors at the same time as strengthening co-operation between these major trading partner countries. [8]

\section{THE ACADEMIC LITERATURE ON RECIPROCAL HEALTH CARE AGREEMENTS}

There is a dearth of academic literature on reciprocal health care agreements. There are three notable exceptions, one in Australia and then two case studies conducted in the context of Brexit and the European Union.

The first and most significant contribution to the literature on this topic is a study conducted by health policy analyst, Simon Barraclough from La Trobe University in Australia in 1990.[11] Thirty years later it remains the most substantial academic examination of this topic. Barraclough's study explained that provisions for bi-lateral cooperation in healthcare were initially included in the Health Insurance Act 1973 by the Labor government in Australia, with the establishment of Australia's universal publicly funded health insurance scheme, Medibank. This overseas component of Medibank, was re-introduced in 1984, with Medicare. Barraclough pointed out that public awareness was an issue at that time as the Federal government was seeking to increase the awareness of overseas travellers of these arrangements and the need to take out appropriate travel insurance. [1 1 ]

Barraclough's study pointed out that Australia's policy on RHCAs was based on two premises: first, that agreements would only be negotiated with countries with comparable national healthcare systems with centralised authority and universal health coverage; and secondly, that the arrangements would have to be 'revenue neutral'. [11] In the first regard, Australia has been unable to negotiate a RHCA with Canada, as even though we a share similar systems of universal health insurance this is not administered nationally in Ottawa, but by each individual province.
We turn now to the principle of "revenue neutrality", which obviated the need for record keeping and financial transfers. This principle allows for the administration of agreements to be simople and cost-free. It should be noted that while the two-way movements of visitors between Australia and the United Kingdom were comparable in 1990, Australia saw six times as many visitors from Sweden, as vice versa, and twice as many New Zealanders visiting Australia, as Australians heading across the Tasman Sea. [1 1] In this regard, Barraclough noted that Australia would be disinclined to enter into an agreement with Japan, for example, as it would have been disproportionately costly to extend reciprocal healthcare benefits to Japanese visitors; Australia's largest single source of visitors at the time, which led to an imbalance of 10:1 in terms of more Japanese entering Australia on shortterm visas. Of course Barraclough's study was conducted before Australia entered into Free Trade Agreements with South Korea (12 December 2014), Japan (15 January 2015) and China (20 December 2015) which would enhance considerations of health diplomacy and strengthening trade and people-to-people links.

The other notable studies of reciprocal health care agreements were conducted in the UK within the context of Brexit. The first case study was conducted by Tamara Hervey, professor of European Union (EU) Law at the University of Sheffield, and published in the British Medical Journal in 2018. [12] Hervey's case study investigated how this policy was actually implemented in respect of EU visitors to the UK, where EU visitors enjoyed similar access to 'immediately needed' National Health Service (NHS) health care available to UK residents. Prior to Brexit, in 2020, there were agreements between 27 European Union nations for nationals residing in or visiting the UK, and vice versa, who were entitled to healthcare under EU law. Reciprocity is reflected in this EU Law as well as in the European Health Insurance Card (EHIC) system, wherein people are entitled to medical treatment as if they were a national of the country providing it, as well as that of the "home country" where the patient has paid tax or national insurance. [12]

The other case study conducted in the UK, by Sheaff, in 1997, was also conducted prior to Brexit. This case study of policy implementation found 'In the case of healthcare access for EU visitors to the UK, '... an implementation surplus ... evident rather than an implementation deficit'. [13] Hence, in the UK, the reciprocal health care 
arrangements were actually being implemented in a more generous way than policy-makers had anticipated.

The other conclusion to note from the academic literature is Barraclough's observation:

'In terms of Australia's relations with the Asia-Pacific region it is significant that not a single reciprocal health care agreement has been negotiated with countries in this region'. [11]

This is despite the fact that the top ten sources of visitors to Australia include no less than 7 Asian countries: China, Japan, Singapore, Malaysia, India, Hong Kong, and South Korea. Thus, while Australia's in-bound visitor numbers and free trade agreements are skewed towards Asia (plus New Zealand and the USA), Australia's reciprocal health care agreements remain firmly oriented towards Europe (and New Zealand). This study aims to tackle this challenge through an examination of the feasibility of a potentia RHCA between Australia and South Korea.

\section{DESIGN AND SETTING}

The study utilised social scientific research methods and analysis. Quantitative and qualitative data encompass secondary data, official statistics, documents, media, and literature including grey literature on this topic.

Document analysis concentrated on official materials obtained from the Australian Ministry of Health, the Australian Ministry of Foreign Affairs, the Australia-Korea Foundation of the Australian Ministry of Foreign Affairs and Trade, the Australian Consulate and Embassy of Australia, and official documents and press releases of the Ministry of Foreign Affairs of Korea.

We analysed the data using thematic analysis. To begin with, we collected and gathered the relevant secondary data, such as immigration data and other official statistics. Then we conducted thematic analysis of reports and policy documents; in which we looked into Australia's RHCA, by country, year, who is covered, what services are covered and not covered, and how costs are reduced. We also examined media reports relevant to Australia's RHCAs. Hence, the methodology comprised secondary data analysis and document analysis,

\section{FINDINGS}

According to Barraclough [11] the preconditions for a potential RHCA are considered in the following twin terms: comparable national healthcare systems and universal health coverage; and balance of visitors between Australia and South Korea (fiscal neutrality). We address each of these considerations in turn.

\section{Comparable national healthcare systems and universal health coverage}

Australia and South Korea have similarities as regards to universal health coverage and population health amongst the two countries. [14] It is no exaggeration to say that Australia and South Korea share universal health coverage in the provision of universal access to basic affordable healthcare services. In the same vein, population health similarities are evident in the similarity in social structure and phenomena such as the age-structured population, the decreasing birth rate and extension of average life expectancy. [8] These considerations were relevant in the design and justification of the study, as the basis for a potential RHCA.

\section{Balance of visitors between Australia and South Korea (fiscal neutrality)}

The population of Australia is about 25 million, which is about half the population of South Korea. However, the size of Australia is 35 times that of the Korean peninsula. [15]

First, we need to consider the 'cost-waiver principle'. The principle refers to states as regards to what must be in line so as there is absence of administrative costs in the two countries. [16] This is a basic prerequisite of RHCAs, and it is pointed out that if the administrative burden is too much or the administrative procedure is too complicated, the feasibility of the agreement will be reduced. A related administrative cost has to do with the cost balance of pharmaceutical drugs. In this sense, should the cost balance of the pharmaceutical drugs be not correct or imbalanced, it would be necessary to use one's own contribution. However, if the equity of health care coverage cannot be achieved, it is necessary to adjust the level of coverage and the scope of the beneficiaries. [17]

Our findings show that Australians residing in South Korea comprise mainly young travellers, students, business people and teachers of English. In Australia, on the other hand, 
increasing numbers of Koreans in Australia, especially since the KAFTA, comprise mainly working holiday visa holders ("Warholers"), plus tourists, students and businesspeople.

The first finding is comparability of universal health coverage and national healthcare systems between Australia and South Korea. Furthermore, fiscal neutrality is feasible due to the the balance of visitors between Australia and South Korea.

\section{DISCUSSION}

The findings from this study reveal that Australia and South Korea share comparable national healthcare systems and universal health coverage. This study reveals also that there is potential for fiscal neutrality, as there is a balance of visitors between Australia and South Korea.

This study has unearthed additional considerations, in particular, in the case of "Warholers" in Australia. Most of the young working holiday visa holders in Australai do not take out travel health insurance due to the fact that there is no compulsory provision for health care insurance for them. Even in the case that they have joined such insurance, it would not be of assistance when the healthrelated problems arise due to inadequate coverage. [5, 17] Notably, young South Koreans who came to Australia as "Warholers" have limited access to health care services because they have insufficient economic circumstances, and hence travel health insurance. $[5,17]$

In respect to the administrative and legal-technical aspects of a potential health care agreement, the process of signing and ratification of a RHCA needs to be cognisant of the relevant legislation. In Australia, the Health Insurance Act 1973 enables health care agreements with 11 nations, however, Korea has no similar legislation in place. [18] Therefore, South Korea would need to build a broader consensus on the need for a RHCA in full, based on the precedent of Australia's agreements with other nations, as well as on the Korean Pension Act, which has enabled reciprocal (equal treatment among the countries) pension agreements with 28 nations through an exceptive clause. Thus, active government commitment and involvement of the Ministry of Health and the Department of Foreign Affairs and Trade in Australia, and of the Ministry of Health \& Welfare and Ministry of Foreign Affairs in Korea, would be essential for a successful RHCA process to come to fruition.

\section{CONCLUSIONS}

On the positive side of the ledger, Australia and South Korea share comparable national healthcare systems and universal health coverage. In addition, there is indeed an increase of exchanges between both countries due to the free trade agreement signed between Australia and South Korea in 2014. [4, 19] And, in terms of reciprocity there are similar numbers of visitors each year between Australia and South Korea (close to a quarter of a million visitors each year). Thus, the two major considerations outlined in Barraclough's [11] seminal study of reciprocal health care agreements have been satisfied.

This study has further unearthed two considerations however, that point to the limited feasibility of a reciprocal health care agreement between Australia and South Korea. The first concerns the significant number of "Warholers", who come to Australia every year from South Korea, as they have limited economic resources and hence inadequate coverage from their travel health insurance. This could challenge the notion of fiscal neutrality.

Furthermore, while Australia has legislation in place that supports reciprocal health care agreements with 11 countries, South Korea does not have enabling legislation in place. While South Korea has mutual social security agreements in place, for the conclusion of a RHCA, new legislation would be required. What follows afterwards would be the requirement for concerted efforts on the part of the Ministries of Foreign Affairs and Health in both countries. While a potential RHCA between Australia and South Korea would constitute a significant step forward in strengthening people-to-people links between these two significant trading partners in the spirit of health diplomacy, the feasibility is very low indeed. Moreover, as it happens, in the COVID-19 context, Australia has substantially closed its international borders. Thus, we do not anticipate Australia negotiating a reciprocal health care agreement with countries in the Asia-Pacific region, in the foreseeable future. 


\section{References}

1. Gen S, Wright AC. Policy Advocacy Organizations: A Framework Linking Theory and Practice. Journal of Policy Practice. 2013;12(3):163-93.

2. Australian-Government-Services-Australia. Reciprocal Health Care Agreements Australia 2019 [Available from:

https://www.servicesaustralia.gov.au/individuals/servi ces/medicare/reciprocal-health-care-agreements.

3. Siriwardana M. Australia's new Free Trade Agreements with Japan and South Korea: Potential Economic and Environmental Impacts. Journal of Economic Integration. 2015;30(4):616-43.

4. DFAT. Korea-Australia Free Trade Agreement 2014 [Available from:

https://www.dfat.gov.au/trade/agreements/inforce/kafta/Pages/korea-australia-fta.

5. MOFA. Ministry of Foreign Affairs Working Holiday Info Center. Ministry of Foreign Affairs; 201717 February 2020.

6. KTO. Monthly Statistics of Tourism KTO (Korea Tourism Organization); 2019 [Available from: https://kto.visitkorea.or.kr/eng/tourismStatics/keyFacts LKoreaMonthlyStatistics/eng/inout/inout.kto.

7. ABS. 3401.0 - Overseas Arrivals and Departures, Australia, Nov 2019: ABS (Australian Bureau of Statistics); 2019)

8. Lee HY, Park EO. The Feasibility of Reciprocal Health Care Agreements between South Korea and Australia. The Korean Journal of Health Service Management. 2017;1 1 (4):225-37.

9. Ki-Sung K. Australian Rural Warholer $66 \%$ "feels exploited"... Asian vulnerabilities, including Korea (호주농촌 워홀러 $66 \%$ "착취 느껴"...한국 등 아시아계 취약) 2016 [Available from: https://www.yna.co.kr/view/AKR20161018044200093.

10. Australian-Immigration. Visitor Visa Report. 2015.

11. Barraclough S. Reciprocal health care agreements and Australian health policy. Australian Health Review 1990;14(4):413-21.

12. Hervey TK. Reciprocal healthcare arrangements after Brexit. BMJ. 2018;363: k4727.

13. Sheaff R. Healthcare access and mobility between the UK and other European Union states: an 'implementation surplus'. Health Policy. 1997;42(3):239-

53.
14. Health-and-Welfare Ministry. Comparison of Healthcare Systems in South Korea and Australia. Unpublished documents in the Ministry of Health and Welfare. Canberra, Australia: Ministry of Health and Welfare - Australia; 2016.

15. ABS. 3101.0 - Australian Demographic Statistics, Dec 2019 Australia: ABS (Australian Bureau of Statistics); 2019 [Available from: https://www.abs.gov.au/AUSSTATS/abs@.nsf/mf/3101. o.

16. Ministry-of-Trade. The number of Australian by stay qualification. Ministry of Trade, Industry and Energy (Korean); 2014.

17. Short S, Lee HY, Lee MJ, Park EO. The Feasibility of a Reciprocal Health Care Agreement (RHCA) between Australia and Korea. Barton ACT: The Australia-Korea Foundation; 2015-2016.

18. Briggs $D$, Isouard $G$. The Language of Health Reform and Health Management: critical issues in the management of health systems. Asia Pacific Journal of Health Management. 2016;1 1 (3):38-44.

19. Quansah KA, Ahn WC. The Effect of the KoreaAustralia Free Trade Agreement (KAFTA) on the KoreaAustralia Trade Structure. The Asian Journal of Shipping and Logistics. 2017;33(4):229-35.

\section{LIST OF ABBREVIATIONS}

AKF: Australia-Korea Foundation, Department of Foreign Affairs and Trade, Australia

EU: European Union

KAFTA: Korea Australia Free Trade Agreement

NHS: National Health Service

RHCA: Reciprocal Health Care Agreement

\section{DECLARATIONS}

In this study data were accessed and obtained from publicly available policy documents, official statistics and the media.

\section{CONSENT FOR PUBLICATION}

The authors consent for publication.

Availability of data and materials

Data and materials are publicly available. 


\section{COMPETING INTERESTS}

The authors declare no competing interests.

\section{FUNDING}

Short S, Lee HY, Lee MJ, Park EO. The Feasibility of a Reciprocal Health Care Agreement (RHCA) between Australia and Korea. Barton ACT: The Australia-Korea Foundation; 2015-2016.

\section{AUTHORS' CONTRIBUTIONS}

Professor Stephanie Doris Short, the University of Sydney led the study on which this paper is based. Prof Short contributed to the design of the overall study, interviews, data analysis and writing.

Professor Hyo-Young Lee, Dongseo University contributed to the conception and design of the study and conduct of the literature review, interviews and data collection.

Dr Mi-Joung Lee Physiotherapy, the University of Sydney contributed to conduct of the interviews, data collection and data analysis.

Professor Eunok Park from Jeju National University in Korea contributed to the design of the study, conduct of the interviews, analysis and writing.

Dr Farah Purwaningrum, Sydney Asia Pacific Migration Centre, the University of Sydney, contributed to the literature review, data analysis and writing.

\section{ACKNOWLEDGEMENTS}

We acknowledge funding obtained from the AustraliaKorea Foundation in the Australian Department of Foreign Affairs and Trade for making this study possible. We thank also key informants in Australia and South Korea for their time and invaluable expertise. 